\title{
NON PERFORMING FINANCING PADA BANK UMUM SYARIAH DI INDONESIA
}

\author{
Eka Prasetya Ningrum \\ Email: ekaningrum038@gmail.com \\ Fakultas Ekonomi/Akuntansi/Universitas Islam Batik Surakarta \\ JL. KH. Agus Salim No. 10 \\ Yuli Chomsatu Samrotun \\ Email: chom_satoe@gmail.com \\ Fakultas Ekonomi/Akuntansi/Universitas Islam Batik Surakarta \\ JL. KH. Agus Salim No. 10 \\ Suhendro \\ Email: dro_s@yahoo.com \\ Fakultas Ekonomi/Akuntansi/Universitas Islam Batik Surakarta \\ JL. KH. Agus Salim No. 10
}

\begin{abstract}
ABSTRAK
Dalam memberikan pembiayaan bank tidak lepas dari non performing financing dalam memberikan pembiayaan. Tujuan dari penelitian ini adalah untuk mengetahui dan menganalisis bagaimana pengaruh rasio keuangan (BOPO, CAR, ROA, dan FDR) terhadap non performing financing pada Bank Umum Syariah. Populasi dalam penelitian ini adalah Bank Umum Syariah yang terdaftar di Otoritas Jasa Keuangan (OJK) periode 2012-2018. Teknik pengambilan sampel menggunakan metode purposive sampling dan didapat 11 sampel. Metode analisis menggunakan analisis regresi linier berganda. Hasil analisis data menunjukkan bahwa variabel CAR, ROA, dan FDR berpengaruh negatif terhadap non performing financing, sedangkan variabel BOPO tidak berpengaruh terhadap non performing financing. Perbankan dalam menjalankan usahanya harus dapat menjaga nilai rasio yang dapat meningkatkan non performing finacing.
\end{abstract}

Kata kunci : Non-Performing Financing; BOPO; CAR; ROA; FDR

\begin{abstract}
In providing bank financing, it cannot be separated from funding non-performing in offering aid. The purpose of this study is to find out and analyze how the influence of financial ratios (BOPO, CAR, ROA, and FDR) on non-performing financing at Islamic Commercial Banks. The population in this study was a Sharia Commercial Bank registered with the Financial Services Authority (OJK) for the 2012-2018 period. The sampling technique uses a purposive sampling method, and 11 samples are obtained. The method of analysis uses multiple linear regression analysis. The results of data analysis showed that the CAR, ROA, and FDR variables had a negative effect on non-performing financing. In contrast, the BOPO variable had no impact on funding non-performing. Banks in running their business must be able to maintain the value of the ratio that can increase non-performing financing.
\end{abstract}

Keywords: Non-Performing Financing; BOPO; CAR; ROA; FDR 


\section{PENDAHULUAN}

Perbankan di Indonesia saat ini sudah cukup pesat, bukan hanya bank konvensional tapi juga bank Syariah yang hampir diseluruh Indonesia ada. Otoritas jasa keuangan (OJK) melaporkan, kinerja pertumbuhan kredit perbankan nasional sepanjang tahun 2016 belum memuaskan. Sepanjang bulan Januari hingga Desember 2016, pertumbuhan kredit perbankan tercatat sebesar 7,87\%. Adapun rasio kredit bermasalah perbankan tahun 2016 masih kisaran aman. Menurut Muliaman D Hadad selaku Ketua Dewan Komisioner OJK menyebutkan rasio NPL gross tahun 2016 mencapai 2,93\%. Kondisi ini berpengaruh terhadap return on asset (ROA) perbankan yang tercatat sebesar 2,23\% angka ini turun dibandingkan tahun 2015 sebesar 2,32\%. (https://money.kompas.com: 3 November 2019).

Asosiasi Bank Syariah Indonesia (Asbisindo) optimis kinerja perbankan Syariah akan terus meningkat. Total asset ditargetkan tumbuh sebesar 12-15\% atau Rp. 35 triliun hingga 40 triliun. pembiayaan perbankan Syariah tahun 2017 mencapai 12,91\% menjadi 235,01 triliun. (https://money.kompas.com: 3 November 2019)

Rasio pembiayaan bermasalah atau non performing financing bank Syariah per Oktober 2017 masih dikisaran 4,12\%. Menurut Ahmand Soekro selaku Kepala Departemen Perbankan Syariah Otoritas Jasa Keuangan (OJK) menargetkan untuk tahun depan rasio NPF bisa lebih baik. Hingga Oktober 2017 jumlah pembiayaan yang diberikaan oleh bank Syariah tercatat Rp. 281,86 triliun. Lalu untuk dana pihak ketiga (DPK) tercatat Rp. 325,69 triliun. Jumlah rekening DPK tercatat 26,57 juta dan rekening pembiayaan 5,71 juta, kemudian total asset bank Syariah sebesar Rp. 406,23 triliun. (http://m.detik.com: 5 November 2019)

Menurut Wimboh selaku Ketua Dewan Komisioner Otoritas Jasa Keuangan (OJK), sampai akhir Februari 2018, asset bank Syariah tercatat tumbuh 20,65\% secara year on year (YoY) menjadi Rp. 429,36 triliun, "Pertumbuhan asset tersebut seiring dengan pertumbuhan dana pihak ketiga (DPK) yang mencapai 18,1\% menjadi Rp. 339,05 triliun" ujar Wimboh. Rasio keuangan perbankan Syariah menurut Wimboh, terpantau dalam kondisi baik. Rasio kecakupan modal (CAR) terjaga sebesar $18,62 \%$. Sementara rasio pembiayaan bermasalah (non performing financing) tercata sebesar $4,31 \%$ atau berada dibawah ambang batas aman OJK sebesar $5 \%$. (http://m.cnnindonesia.com: 5 November 2019)

Menurut Haifa \& Wibowo (2015) dan Purnamasari \& Musdholifah (2016) dalam penelitiannya menunjukkan bahwa CAR tidak berpengaruh terhadap non performing financing. 
Menurut Firdaus (2015) dalam penelitian menunjukkan bahwa CAR memiliki pengaruh terhadap non performing financing, penelitian ini sejalan dengan penelitian yang dilakukan Effendi et.al (2017). Havidz \& Setiawan (2015) dalam penelitiannya menunjukkan bahwa FDR tidak berpengaruh terhadap non performing financing sejalan dengan penelitian yang dilakukan oleh Damanhur et.al (2018), sedangkan penelitian yang dilakukan oleh Pradana (2018) dan Nurhaliza et.al (2018) menunjukkan bahwa FDR memiliki pengaruh terhadap non performing financing.

Menurut Havidz \& Setiawan (2015) dalam penelitiannya juga menunjukkan bahwa ROA tidak memiliki pengaruh terhadap non performing financing. Berbeda dengan Effendi et.al (2017), menunjukkan bahwa ROA memiliki pengaruh terhadap non performing financing. Dalam penelitian Purnamasari \& Musdholifah (2016) menunjukkan bahwa BOPO tidak berpengaruh terhadap non performing financing, sedangkan dalam penelitian Auliani \& Syaichu (2016) menunjukkan bahwa BOPO memiliki pengaruh terhadap non performing financing. Berdasarkan latar belakang yang diuraikan diatas maka penelitian ini bertujuan untuk meneliti Non Performing Financing Pada Bank Umum Syariah di Indonesia. Tujuan penelitian ini adalah untuk mengetahui dan menganalisis bagaimana pengaruh rasio keuangan (BOPO, CAR, ROA, dan FDR) terhadap non performing financing pada Bank Umum Syariah periode 2012-2018.

\section{METODE PENELITIAN}

Jenis penelitian ini merupakan penelitian kuantitatif dan variabel dalam penelitian ini adalah variabel BOPO $\left(\mathrm{X}_{1}\right)$, CAR $\left(\mathrm{X}_{2}\right)$, ROA $\left(\mathrm{X}_{3}\right)$, dan FDR $\left(\mathrm{X}_{4}\right)$ untuk variabel independen, sedangkan untuk variabel dependennya adalah non performing financing (Y). Sumber data yang digunakan dalam penelitian menggunakan data sekunder yang diperoleh dari laporan keuangan tahunan perbankan Syariah yang terdaftar di Otoritas Jasa Keuangan (OJK). Instrument penelitian yang digunakan adalah dokumentasi. Penelitian ini menggunakan populasi perusahaan Bank Umum Syariah yang terdaftar di Otoritas Jasa Keuangan (OJK) periode 2012-2018, untuk pemilihan sampel menggunakan metode purposive sampling dengan kriteria, (1) Perusahaan Bank Umum Syariah yang terdaftar di Otoritas Jasa Keuangan (OJK) selama periode 2012-2018 dan melaporan keuangannya secara rutin dengan data mudah didapat. (2) Data yang digunakan bebas dari outlier data. Metode analisis data yang digunakan adalah analisis regresi linier berganda. Model persamaan regresi linier berganda sebagai berikut:

$\mathrm{Y}=\alpha+\beta 1 B O P O+\beta 2 \mathrm{CAR}+\beta 3 \mathrm{ROA}+\beta 4 \mathrm{FDR}+\mathrm{e}$

Keterangan : 


\begin{tabular}{|c|c|}
\hline Y & $=$ Non Performing Financing \\
\hline BOPO & $=$ Operational Cost to Operating Income \\
\hline CAR & $=$ Capital Adequacy Ratio \\
\hline ROA & $=$ Return on Assets \\
\hline FDR & $=$ Financing to Deposit Ratio \\
\hline$\beta 1 \beta 2 \beta 3 \beta 4$ & $=$ koefisien regresi parsial \\
\hline & $=$ error \\
\hline
\end{tabular}

\section{HASIL DAN PEMBAHASAN}

\section{A. Analisis Statistik Deskriptif}

Dari hasil penelitian menunjukkan bahwa variabel BOPO memiliki nilai mean sebesar 78.0311, nilai maksimum 133.44, nilai minimum sebesar 14.81 untuk std. deviation BOPO sebesar 24.37898. Variabel CAR memiliki nilai mean sebesar 16.5010, nilai maksimum 36.78, nilai minimum sebesar 1.75, dan untuk nilai std. deviation sebesar 7.86249. variabel ROA dengan nilai mean sebesar 0.6152, nilai maksimum sebesar 3.10, nilai minimum sebesar -7.34, serta nilai std. deviation sebesar 1.41639. variabel FDR nilai mean sebesar 94.5719, nilai maksimum sebesar 163.31, nilai minimum sebesar 31.00, dan std. deviation sebesar 25.49995. Variabel dependen NPF memiliki nilai mean sebesar 4.0775, nilai maksimum sebesar 12.68, nilai minimum sebesar 0.20 , serta nilai std. deviation sebesar 2.52746 .

Tabel 1. Uji Statistik Deskriptif

\begin{tabular}{lccccc}
\hline Variabel & $\mathrm{N}$ & Minimum & Maximum & Mean & Std. Deviation \\
\hline BOPO (X1) & 58 & 14.81 & 133.44 & 78.0311 & 24.37898 \\
CAR (X2) & 58 & 1.75 & 36.78 & 16.5010 & 7.86249 \\
ROA (X3) & 58 & -7.34 & 3.10 & .6152 & 1.41639 \\
FDR (X4) & 58 & 31.00 & 163.31 & 94.5719 & 25.49995 \\
NPF (Y) & 58 & .20 & 12.68 & 4.0775 & 2.52746 \\
\hline
\end{tabular}

Sumber: data sekunder yang diolah 2019

\section{B. Uji Asumsi Klasik}

\section{Analisis Uji Normalitas}

Tabel 2. Uji Normalitas

$\begin{array}{llll}\text { Variabel } & \text { Sig. } & \text { Syarat } & \text { Kesimpulan }\end{array}$


Jurnal Ekonomi Pembangunan Vol. 5, No.2 (2019) 127-137

$\begin{array}{llll}\text { Unstandarized Residual } \quad .200 \quad>0,05 & \text { Berdistribusi normal }\end{array}$

Sumber: data sekunder yang diolah 2019

2. Analisis Uji Multikolierlitas

Tabel 3. Uji Multikolinearitas

\begin{tabular}{lccccc}
\hline \multicolumn{1}{c}{ Variabel } & Tolerance & Syarat & VIF & Syarat & Kesimpulan \\
\hline BOPO (X1) & .936 & $>0,1$ & 1.068 & $<10$ & Tidak terjadi multikolinearitas \\
CAR (X2) & .945 & $>0,1$ & 1.058 & $<10$ & Tidak terjadi multikolinearitas \\
ROA (X3) & .928 & $>0,1$ & 1.077 & $<10$ & Tidak terjadi multikolinearitas \\
FDR (X4) & .917 & $>0,1$ & 1.09 & $<10$ & Tidak terjadi multikolinearitas \\
\hline
\end{tabular}

Sumber: data sekunder yang diolah 2019

\section{Analisis Uji Autokorelasi}

Tabel 4. Uji Autokorelasi

\begin{tabular}{ccc}
\hline Syarat & Hasil & Kesimpulan \\
\hline DU $<$ DW $<4-\mathrm{DU}$ & $1.7259<2.237<2.2741$ & Tidak terjadi autokorelasi \\
\hline
\end{tabular}

Sumber: data sekunder yang diolah 2019

\section{Analisis Uji Heteroskedastisitas}

Tabel 5. Uji Heteroskedastisitas

\begin{tabular}{cccl}
\hline Variabel & Sig & Syarat & \multicolumn{1}{c}{ Kesimpulan } \\
\hline BOPO (X1) & .787 & $>0,05$ & Tidak terjadi heteroskedastisitas \\
CAR (X2) & .732 & $>0,05$ & Tidak terjadi heteroskedastisitas \\
ROA (X3) & .551 & $>0,05$ & Tidak terjadi heteroskedastisitas \\
FDR (X4) & .837 & $>0,05$ & Tidak terjadi heteroskedastisitas \\
\hline
\end{tabular}

Sumber: data sekunder yang diolah 2019 


\section{Analisis Regresi Linier Berganda}

\section{Model Regresi}

Tabel 6. Model Regresi

\begin{tabular}{lcc}
\hline & Model & B \\
\hline Constant & 10.763 \\
BOPO (X1) & -.004 \\
CAR (X2) & -.066 \\
ROA (X3) & -1.347 \\
FDR (X4) & -.047 \\
\hline
\end{tabular}

Sumber: data sekunder yang diolah 2019

Berdasarkan tabel di atas maka dapat dijelaskan persamaan regresi linier berganda sebagai berikut: $\mathrm{Y}=10,763-0,004 \mathrm{X} 1-0,066 \mathrm{X} 2-0,347 \mathrm{X} 3-0,047 \mathrm{X} 4+\mathrm{e}$. Konstanta sebesar 10,763 menunjukkan jika nilai BOPO, CAR, ROA, dan FDR adalah nol, maka non performing financing yang terjadi sebesar 10,763\%. Koefosien regresi BOPO sebesar -0,004 menyatakan bahwa setiap penambahan BOPO sebesar 1\%, maka akan menurunkan non performing financing sebesar -0,004\%. Koefisien regresi CAR sebesar -0,066 menyatakan bahwa setiap penambahan CAR $1 \%$, akan menurunkan non performing financing sebesar -0,066\%. Koefisien regresi ROA sebesar -1,347 menyatakan bahwa setiap penambahan ROA 1\%, maka akan menurunkan non performing financing sebesar $-1,347 \%$. Koefisien regresi FDR sebesar -0,047 menyatakan bahwa setiap penambahan FDR sebesar 1\%, maka akan menurunkan non performing financing sebesar $0,047 \%$.

\section{Analisis Uji F}

Tabel 7. Uji F

\begin{tabular}{ccccc}
\hline F Hitung & F Tabel & Sig. & Syarat & Kesimpulan \\
\hline 23.667 & 2.546 & .000 & $<0,05$ & Model layak \\
\hline
\end{tabular}

Sumber: data sekunder yang diolah 2019

\section{Analisis Uji t}

Tabel 8. Uji Hipotesis

\begin{tabular}{cccccc}
\hline Hipotesis & T Hitung & T tabel & Sig & Syarat & Kesimpulan \\
\hline H1 & -.412 & -2.006 & .682 & $<0,05$ & Ditolak \\
H2 & -2.423 & -2.006 & .019 & $<0,05$ & Diterima \\
H3 & -8.839 & -2.006 & .000 & $<0,05$ & Diterima
\end{tabular}



$\mathrm{H} 4$
$-5.570$
$-2.006$
.000
$<0,05$
Diterima

Sumber: data sekunder yang diolah 2019

\section{Analisis Uji Koefisien Determinasi (R2)}

Tabel 9. Uji Koefisien Determinasi

\begin{tabular}{cc}
\hline Adjusted R Square & Kesimpulan \\
\hline 0.614 & Berpengaruh sebesar 61,4\% \\
\hline
\end{tabular}

Sumber: data sekunder yang diolah 2019

\section{BOPO berpengaruh terhadap NPF}

BOPO merupakan rasio yang digunakan untuk mengetahui seberapa efisiensi perbankan dalam menjalankan kegiatan usahanya. Hasil penelitian menunjukkan bahwa variabel BOPO memiliki nilai $t_{\text {hitung }}>t_{\text {table }}$ sebesar $-0,412>-2,006$ dengan sig sebesar 0,682 $>0,05$. Dari hasil penelitian ini menunjukkan bahwa variabel BOPO secara parsial tidak terdapat pengaruh terhadap non performing financing. Ini karena bank Syariah dalam melakukan pengelolaan dan pengawasan dalam kegiatan usahanya mengenai seberapa besar beban yang dikeluarkan oleh bank dan seberapa besar bank memiliki pendapatan yang dimana tidak ada keterkaitannya dengan pembiayaan yang diberikan oleh pihak bank. Penelitian ini sejalan dengan penelitian yang dilakukan oleh Purnamasari \& Musdholifah (2016).

\section{CAR berpengaruh terhadap NPF}

CAR merupakan rasio yang digunakan untuk mengetahui seberapa besar kemampuan perbankan dalam menyediakan dana untuk mengatasi risiko yang mungkin terjadi di dalam kegiatan perbankan. Hasil penelitian menunjukkan bahwa thitung sebesar $-2,423$ sedangkan $t$ tabel sebesar -2,006 ini menunjukkan bahwa thitung $<t_{\text {table }}$ dengan nilai sig sebesar 0,019 $<0,05$. Hasil penelitian ini menunjukkan bahwa CAR memiliki pengaruh negative terhadap non performing financing. Ini menandakan bahwa semakin tinggi nilai CAR maka dapat menurunkan nilai non performing financing, dan sebaliknya semakin kecil nilai CAR maka nilai non performing financing akan meningkat. Hal ini dikarenakan bank dalam menjalankan kegiatan usahanya dalam memberikan pembiayaan yang mungkin dalam kegiatan pembiayaan adanya risiko kurang lancar, diragukan, dan macet bank yang memiliki nilai CAR yang tinggi dapat mengurangi risiko ini dengan dana yang ada, dengan begitu nilai non performing financing akan menurun. 
Penelitian ini sejalan dengan penelitian yang dilakukan oleh Aryani et.al (2016) dan Amelia (2019).

\section{ROA berpengaruh terhadap NPF}

ROA merupakan rasio yang digunakan untuk mengetahui seberapa mampu perusahaan dalam menghasilkan laba sebesar-besarnya. Hasil penelitian menunjukkan bahwa variabel ROA dengan $t_{\text {hitung }}$ sebesar -8,839 dan $t_{\text {table }}$ sebesar -2,006 yang berarti thitung $<t_{\text {table }}$ dengan nilai sig 0,000 < 0,05 . Hasil penelitian ini menunjukkan bahwa ROA secara parsial berpengaruh negative terhadap non perfoming financing. ROA yang semakin tinggi menunjukkan bahwa dalam menghasilkan laba cukup baik, semakin tingginya ROA ini maka akan menurunkan nilai non performing financing. Hasil ini dapat disebabkan karena bank dalam hal kegiatannya sebagai Lembaga yang menghipun dana dan mengelola dana dan dalam kegiatannya memberikan pembiayaan kepada nasabah yang memerlukan dana, bank dalam melakukan pengendalian dan pengawasan terhadap nasabah tersebut terbilang baik dan tingginya non performing financing dapat berkurang. Penelitian ini sejalan dengan penelitian yang dilakukan oleh Buana (2018) dan Effendi et.al (2017).

\section{FDR berpengaruh terhadap NPF}

FDR merupakan rasio yang digunakan untuk mngetahui seberapa besar perbankan dalam memberikan pembiayaan dengan menggunakan dana pihak ketiga. Hasil penelitian menunjukkan bahwa nilai thitung sebesar -5,570 sedangkan nilai $t_{\text {table }}$ sebesar -2,006 yang berarti berarti $t_{\text {hitung }}<$ table dengan nilai sig sebesar $0,000<0,05$. Hasil penelitian ini menunjukkan bahwa FDR secara parsial berpengaruh negative terhadap non performing financing. Semakin tingginya nilai FDR maka nilai non performing financing akan turun. Hal ini sebabkan karena bank dalam menjalankan kegiatan pembiayaan dengan memberikan dana pihak ketiga dapat dikelola dengan baik dan dapat menjaga rendahnya nilai non performing financing. Penelitian ini sejalan dengan penelitian yang dilakukan oleh Vanni \& Rokhman (2017) dan Wulandari et.al (2019) yang berpendapat adanya pengaruh negative FDR terhadap non performing financing.

\section{KESIMPULAN DAN SARAN}

\section{Kesimpulan}

Perbankan dalam menjalankan usahanya tidak lepas dari adanya kendala yang dihadapi khusus nya kendala non performing financing. Hal ini disebabkan bank sebagai Lembaga yang 
menghimpun dana juga melakukan kegiatan pembiayaan dalam usaha dan ini merupakan risiko yang cukup tinggi dari kegiatan tersebut. Agar bank dapat menjaga non performing financing ditingkat yang rendah maka perbankan harus memperhatikan rasio-rasio yang mempengaruhi non performing financing. Dari hasil penelitian yang telah dilakukan dapat disimpulkan bahwa:

1. Berdasarkan uji F yang telah dilakukan menunjukkan bahwa variabel BOPO, CAR, ROA, dan FDR secara simultan berpengaruh terhadap non performing financing.

2. Variabel CAR, ROA, dan FDR secara parsial memiliki pengaruh negative terhadap non performing financing pada Bank Umum Syariah.

3. Variabel BOPO secara parsial tidak memiliki pengaruh terhadap non performing financing pada Bank Umum Syariah.

\section{Saran}

Dari hasil penelitian yang sudah dilakukan peneliti memberikan saran agar setiap perbankan dalam menjalankan usahanya dapat menjaga tingkat kesahatan perbankan dalam hal non performing financing agar masyarakat dan nasabah dapat mempercayai bank Syariah dalam mengelola dana maupun menghimpun dana yang mereka simpan dibank. Serta dalam melakukan penelitian selanjutnya dapat lebih memperluas sampel penelitian tidak hanya diperbankan Syariah yang ada di Indonesia saja.

\section{UCAPAN TERIMA KASIH}

Saya ucapkan terimakasih kepada semua pihak yang telah membantu saya dalam menyelesaikan hasil karya ini teruma terhadap teman-teman saya yang mau berjuang dan bersemangat dalam mendukung hasil karya ini.

\section{DAFTAR PUSTAKA}

Amelia, A. E. (2019). "Pengaruh Capital Adequacy Ratio (CAR), Inflasi dan Financing to Deposit Ratio (FDR) Terhadap Non Performing Financing (NPF) pada Bank Umum Syariah Periode 2015-2017". Jurnal Intelektualita: Keislaman, Sosial, dan Sains. Vol. 8. No. 1 .

Aryani, Y., Anggraeni, L., \& Wiliasih, R. (2016). "Faktor-Faktor yang Mempengaruhi Non Performing Financing pada Bank Umum Syariah Indonesia Periode 2010-2014". Jurnal Al-Muzara'ah. Vol. 4, No. 1. 
Aulia, F. (2016). " Pengaruh CAR, FDR, NPF, dan BOPO Terhadap Profitabilitas (Return On Equity) (Studi Empiris pada Bank Umum Syariah di Indonesia Periode Tahun 20092013)'. Diponegoro Journal of Management, 5(6), 1-10.

Auliani, M. M., \& Syaichu. (2016). "Analisis Pengaruh Faktor Internal dan Faktor Eksternal Terhadap Tingkat Pembiayaan Bermasalah pada Pank Umum Syariah di Indonesia Periode Tahun 2010-2014". DIPONEGORO JOURNAL OF ECONOMICS. Volume 5, Nomor 3.

Buana, M. (2018). "Pengaruh Capital Adequacy Ratio (CAR), Return On Assets (ROA), Financing to Deposite Ratio (FDR) Terhadap Non Performing Financing (NPF) pada BUS di Indonesia Periode 2014-2017". SKRIPSI. IAIN SURAKARTA.

Damanhur, Albra, W., Syamni, G., \& Habibie, M. (2018). "What is the Determinant of Non Performing Financing in Branch Sharia Regional Bank in Indonesia". emeraldinsight Journal.

Effendi, J., Thiarany, U., \& Nursyamsiah, T. (2017). "Factors Influencing Non Performing Financing (NPF) at Sharia Banking". Jurnal Penelitian Sosian Keagamaa. Vol. 25, No. 1 .

Firdaus, R. N. (2015). "Pengaruh Faktor Internal dan Eksternal yang Mempengaruhi Pembiayaan Bermasalah pada Bank Umum Syariah di Indonesia". El-Dinar. Vol. 3, No. 1.

Haifa, \& Wibowo, D. (2015). "Pengaruh Faktor Internal Bank dan Makro Ekonomi Terhadap Non Performing Financing Perbankan Syariah di Indonesia Periode 2010-2014". Jurnal Nisbah. Vol. 1(2): 7487.

Havidz, S. H., \& Setiawan, C. (2015). "Bank Effeciency and non performing financing in the indonesian islamic banks". Asian Journal of Economic Modelling. Vol. 3(3): 61-79.

Jensen, M. C., \& William, H. M. (1976). "Theory of the firm: Managerial Behaviour, Agency Cost and Owenership Structur". journal of financial economics. vol. 3(4): 305-360.

Kasmir. (2012). "Analisis Laporan Keuangan". Jakarta: PT. Raja Grafindo Persada.

Medyawati, H., \& Yunanto, M. (2019). "Factors Influencing Islamic Bank Financing in Indonesia". The Asian Institute of Research Journal of Economics and Business Vol.2, No.1.

Muhammad , \& Ilmi, B. (2018). "The analysis of the effect of Islamic financing and labor relationship development towards nonperforming financing in Islamic banks". Journal of Islamic Accounting and Business Research.

Nurhaliza, S., Kismawadi, E. R., \& Hamid, A. (2018). "Pengaruh Rasio Keuangan Terhadap Non Performing Financing pada PT. Bank Syariah Mandiri Indonesia". Al-Masharif: Jurnal Ilmu Ekonomi dan Keislaman. Vol. 6, No. 2.

Pradana, M. N. (2018). "Pengaruh Likuiditas dan Variabel Eksternal Terhadap Non Performing Financing pada Bank Syariah". EKSIS. Vol. 13, No. 2. 
Purnamasari, A. E \& Musdholifah. (2016). "Analisis Faktor Eksternal dan Internal Bank Terhadap Risiko Pembiayaan Bank Umum Syariah di Indonesia Periode 2012-2015". Juenal Ilmu Manajemen. Vol. 4(2): 425-436.

Supriani , I., \& Sudarsono , H. (2018). "Analisis Pengaruh Variabel Mikro Dan Makro Terhadap NPF Perbankan Syariah di Indonesia". EQUILIBRIUM: Jurnal Ekonomi Syariah. Volume 6, Nomor 1 .

Vanni, K. M., \& Rokhman, W. (2017). "Analisis Faktor-Faktor yang Mempengaruhi Non Performing Financing pada Perbankan Syariah di Indonesia Tahun 2011-2016". EQUILIBRIUM: Jurnal Ekonomi Syariah. Vol. 5, No. 2.

Wulandari, M. V., Suryana, \& Utami, S. A. (2019). "Determinant of Non-performing Financing in Indonesia Islamic Bank ". KnE Social Sciences pages 453-468.

Yanti, E. M., Arfan, M., \& Basri, H. (2018). "The effect of third party funds, financing to deposit ratio and non performing financing toward financing and its impact on profitability of indonesian shariah banking (studies at sharia commercial banks period 2011-2015)". account and financial management journal. Vol. 3 issue 01.

Yusuf, M., \& Surjaatmadja, S. (2018). "Analysis of Financial Performance on Profitability with Non Performance Financing as Variable Moderation (Study at Sharia Commercial Bank in Indonesia Period 2012-2016)". International Journal of Economics and Financial. Vol 8 Issue 4 . 